\title{
OCCUPATION, EXPOSURE TO CHEMICALS, SENSITIZING AGENTS, AND RISK OF MULTIPLE MYELOMA IN SWEDEN
}

Virginia Lope, ${ }^{1,2}$ Beatriz Pérez-Gómez, ${ }^{1,2}$ Nuria Aragonés, ${ }^{1,2}$ Gonzalo López-Abente, ${ }^{1,2}$ Per Gustavsson,, 3 Nils Plato, ${ }^{3,4}$ Jan-Paul Zock, ${ }^{1,5,6}$ Marina Pollán,1,2

${ }^{1}$ CIBER en Epidemiología y Salud Pública (CIBERESP), Madrid, Spain.

${ }^{2}$ Cancer and Environmental Epidemiology Unit, National Center for Epidemiology, Carlos III Institute of Health, Madrid, Spain.

${ }^{3}$ Department of Occupational and Environmental Health, Stockholm Center for Public Health, Stockholm, Sweden.

${ }^{4}$ Division of Occupational and Environmental Health, Department of Public Health Sciences, Karolinska Institutet, Stockholm, Sweden.

${ }^{5}$ Centre for Research in Environmental Epidemiology (CREAL), Barcelona, Spain.

${ }^{6}$ Municipal Institute of Medical Research (IMIM), Barcelona, Spain.

Running title: Multiple myeloma and occupational exposures in Sweden

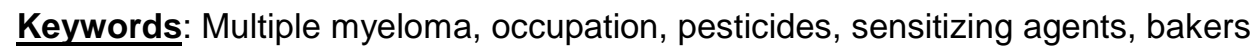

\section{Corresponding author}

Virginia Lope Carvajal

Cancer and Environmental Epidemiology Unit

National Center for Epidemiology

Carlos III Institute of Health

C/ Sinesio Delgado, 6

28029 Madrid, Spain

Tel. : + 34-918222640

Fax: $+34-913877815$

E-mail: vicarvajal@isciii.es 


\section{ABSTRACT}

Background: This study sought to identify occupations with high incidence of multiple myeloma, and investigate possible excess risk associated with occupational exposure to chemicals and sensitizing agents in Sweden.

Methods: An historical cohort of 2,992,166 workers was followed up (1971-1989) through record-linkage with the National Cancer and Death Registries. For each job category, age- and period-standardized incidence ratios and age-period adjusted relative risks of multiple myeloma were calculated using Poisson models. Exposure to chemicals and to sensitizing agents was also assessed, using two job-exposure matrices. Men and women were analyzed separately.

Results: During follow-up, 3,127 and 1,282 myelomas were diagnosed in men and women, respectively. In men, excess risk was detected among working proprietors, agricultural, horticultural and forestry enterprisers, bakers and pastry cooks, dental technicians, stone cutters/carvers, and prison/reformatory officials. In women, this excess was observed among attendants in psychiatric care, metal workers, bakers and pastry cooks, and paper/paperboard product workers. Workers, particularly bakers and pastry cooks, exposed to high molecular weight sensitizing agents registered an excess risk of over $40 \%$ across the sexes. Occasional, though intense, exposure to pesticides was also associated with risk of myeloma in our cohort.

Conclusions: Our study supports a possible etiologic role for farming and use of pesticides in myeloma risk. The high incidence found in both female and male bakers and pastry cooks has not been previously described. Further research is required to assess the influence of high molecular weight sensitizing agents on risk of multiple myeloma.

\section{Introduction}


Multiple myeloma $(\mathrm{MM})$ is a disease of malignant differentiated $B$ lymphocytes. There are no established risk factors other than male gender, age, African American ethnicity, family history of lymphatohematopoietic cancer, and monoclonal gammopathy of undetermined significance. Chronic immune stimulation and autoimmune disorders have been less consistently related $(1,2)$.

Occupational studies have detected excess risk among farmers, mainly attributable to pesticide exposures $(3,4)$. Less consistent positive results have been observed among hairdressers, spray painters, firefighters, workers in the chemical, petroleum, timber, footwear, rubber and plastic industries, and workers exposed to ionizing radiation, asbestos, metals, engine exhausts, and specific solvents such as benzene $(1,2,5)$. Due to the fact that MM is a rare tumor, most occupational-cohort studies lack statistical power, and case-control studies report a low number of exposed workers in certain occupations or chemical exposure categories (1).

This study sought to identify occupations displaying a high risk of MM, and investigate the relationship between $\mathrm{MM}$ and occupational exposure to chemicals and sensitizing agents in a cohort of almost 3 million Swedish workers followed up for 19 years, a cohort in which the relationship between occupation and various tumors had been previously studied $(6,7)$.

\section{Materials and Methods}

The historical cohort of all active Swedish men aged 25-59 years, recorded in the 1960 census, and gainfully employed and over the age of 24 years in the 1970 census (1,890,497 men; 1,101,669 women), was followed up from 1971 to 1989 through record-linkage with the Swedish Cancer Environment Register $(8,9)$ and National Death Registry. This record-linkage has been described in detail elsewhere (9).

The overall person-time that each person contributed to the study was allocated to the corresponding cells of the variables of stratification, namely: occupation; industrial branch; sex; five-year age group; calendar time period; and county of residence in 1970. Whereas, occupations were coded according to 
the Nordic Classification of Occupations at a three-digit level (9), industrial branch was coded on a fourdigit basis, in accordance with the Nordic Registry of Industries (10).

Exposure to 13 chemical agents was assessed by linking any given occupation-industry combination to a qualitative job exposure matrix (JEM) developed for the Swedish workforce (11). This classified combinations as: "unexposed" (under 10\% of workers exposed to levels exceeding 1/10 of the Swedish occupational exposure limit (OEL) for a given substance in 1970); "possible exposure" (10\%-66\% of workers exposed to such levels); and "probable exposure" (over 66\% workers exposed). It covered $73.2 \%$ of the male and $75.2 \%$ of the female cohorts used in this study, as certain combinations of job and industry were not assessed owing to the low number of subjects. The chemicals included were asbestos, chromium/nickel, lead, mercury, metals, oil mist, polycyclic aromatic hydrocarbons, pesticides/herbicides, pesticides/herbicides at peak exposure (mainly sprayers), petroleum products, quartz, solvents, and textile dust. Peak exposure to pesticides/herbicides was solely classified as "possible exposure". Quartz was solely classified as "probable exposure".

Exposure to high molecular weight (HMW) and low molecular weight (LMW) sensitizing agents was assessed by linking the job codes to an asthma-specific JEM (12) adapted to the Nordic Classification of Occupations. HMW agents $(>5 \mathrm{kD})$ included allergenic proteins derived from animals, plants (including flour and latex), micro-organisms or biological enzymes. LMW agents included a variety of highly reactive chemicals, antigenic wood dusts, and metal antigens. For each occupation, a semi-quantitative estimate was included as (i) unexposed, (ii) possibly exposed, and (iii) probably exposed to each category of sensitizing agent.

Age-period standardized incidence ratios (SIRs) were calculated for each occupation, using the whole cohort as reference. Log-linear Poisson models adjusted for geographic area were fitted in order to obtain relative risks (RRs) for: 1) each occupation; 2) possible and probable exposures to a specific chemical compared to zero exposure; and, 3) probable exposures to HMW and LMW sensitizing agents. In these models, the number of expected cases was introduced as an offset (13). As the expected number of cases was computed by taking the age- and period-specific rates of the study cohort as reference, the RR was likewise age- and period-adjusted. Analyses of MM risk by occupation were repeated for the 
subcohort reporting the same occupation in the 1960 and 1970 censuses. In the analysis of exposure to sensitizers, exposed occupations were deemed to be only those that had a high likelihood of exposure, and these were compared with unexposed occupations, thereby increasing the specificity of the study and reducing possible misclassification bias. Given the existence of occupations with exposure to both HMW and LMW allergens, the RRs were calculated by introducing both variables into the model. Due to differences in MM incidence and occupational distribution between the sexes, separate analyses were performed for men and women.

\section{Results}

A total of 3,127 and 1,282 cases of multiple myeloma were diagnosed in men and women, respectively. Only those occupations with at least 5 observed cases were analyzed. Tables 1 and 2 show the SIRs and RRs for all occupational sectors and for occupations with at least 5 observed cases and an $R R>=2.00$, or with at least 10 observed cases and an $R R>=1.20$, in the total cohort or in the subcohort.

In men (Table 1), the only occupational sector with a significant excess risk was the agriculture/forestry/fishing sector, both in the general cohort (RR:1.18; 95\% $\mathrm{Cl}: 1.07-1.30)$ and in the subcohort (RR:1.15; 95\% Cl:1.03-1.28). A significant excess risk was also detected in both analyses among working proprietors, agricultural, horticultural and forestry enterprisers, dental technicians, and prison/reformatory officials. Bakers and pastry cooks (RR:1.53; 95\%Cl:1.02-2.31) and stone cutters/ carvers also displayed a clear excess risk in the cohort, and a high though non-significant risk in the subcohort.

Female workers in production sector II (printing, ceramics, food, paper, rubber and other chemical products) registered a significant excess risk (Table 2), both in the total cohort (RR:1.1.35; 95\%Cl:1.101.66) and in the subcohort (RR:1.53; 95\% Cl:1.04-2.26). Attendants in psychiatric care, toolmakers, machine-tool setters/operators, other engineering/building metal workers, bakers and pastry cooks, and paper/paperboard product workers registered a significant excess risk in the cohort analysis. Similar or even increased risks were detected in the subcohort, though in this case the estimators failed to attain statistical significance. 
Table 3 sets out the RRs of MM in men and women, associated with occupational exposure to chemicals and sensitizing agents. Only those chemicals with at least 10 probable exposed cases are shown. Women were less exposed than men. The only significant excess risk was associated with occasional, though intense, use of pesticides/herbicides by men (RR:1.20; $95 \% \mathrm{Cl}: 1.07-1.34$ ), principally among working proprietors and agricultural/horticultural/forestry enterprisers (data not shown). Exposure to HMW sensitizing agents registered a significant excess risk among male (RR:1.45; 95\% $\mathrm{Cl}: 1.06-1.98)$ and female workers alike (RR:1.59; 95\%Cl:1.02-2.49). Bakers and pastry cooks accounted for about $60 \%$ of exposed cases in both sexes (data not shown).

\section{Discussion}

This cohort study suggests the possibility of an excess risk of MM linked to bakers and pastry cooks of both sexes, as well as an elevated risk in agricultural/horticultural/forestry workers, dental technicians, stone cutters/carvers, and prison/reformatory officials among men, and attendants in psychiatric care, metal workers, and paper workers among women. The results also indicate a positive association with occupational exposure to peak exposures of pesticides among men, and among workers, mainly bakers and pastry cooks, exposed to HMW sensitizers.

Among our study's principal strengths are its considerable size, the stratification of the analysis into men and women, and the possibility of reassessing the results using the subcohort of persons reporting the same occupation in the 1960 and 1970 censuses. Furthermore, our analysis used two complementary approaches to the study of occupational risks associated with MM: on the one hand, we studied the risks linked to specific occupations, and on the other, we assessed the risks associated with exposure to specific agents, using JEMs.

Our study also displays some limitations. First, we were unable to adjust for confounding factors other than age, period and geographical area. Second, occupation was allocated on the basis of subjects' occupational category at the beginning of the study. Nevertheless, there are ecological data to show that the Swedish employment market was quite stable during the study period (14). Moreover, the use of a subcohort with a more specific definition of occupation served to confirm the associations observed in the general cohort. Third, the so-called "mass significance phenomenon" may produce spurious significant 
associations due to multiple comparisons. Among occupations with at least 5 observed cases analyzed in our study, chance would account for 3 occupations with significant excess risk among men and 1 such occupation among women. These figures suggest that chance alone cannot explain all the increased risks found in our study. Finally, the use of job exposure matrices is an imperfect measure for estimating exposure, and generally involves non-differential classification bias. This misclassification, coupled with the impossibility of measuring exposure outside the job setting, would inevitably entail an underestimation of the effect. Yet we feel that, even with this limitation, JEMs offer the advantage of greater statistical power resulting from pooling subjects from different occupations having a similar estimated range of exposure.

In our study a significant excess risk was detected among male agricultural, horticultural and forestry enterprisers. The association between MM and farming has been extensively studied in the literature (4) but as yet the exposures responsible for this association are not sufficiently known. Among the possible etiologic agents, exposure to diesel exhausts, zoonotic virus infections, and exposure to pesticides have all been mooted (3). Indeed, the results of our study reflect an excess risk among workers exposed to pesticides which are used occasionally. Some herbicides have been shown to impair cytokine production and induce immunosuppression (3). Even so, there is no consistent evidence to date of an exposureresponse gradient of or a recognized biologic mechanism for the role of pesticides in MM carcinogenesis (15).

The bakers and pastry cooks in our cohort, male as well as female, registered an elevated risk of MM. In 1970 there were 14924 males and 5126 females employed as bakers/pastry cooks, accounting for $0.7 \%$ of the gainfully employed Swedish population. We found no previous study in the literature that described an association between these professions and MM. Bakers and pastry cooks feature among the occupations exposed to those HMW sensitizing agents for which our study shows a significant association with $\mathrm{MM}$. This result highlights the fact that exposure to HMW agents commonly occurring in the bakery environment may constitute one of the causative factors underlying the excess of myelomas in this group. Among these agents are certain fungal enzymes and flour dust. As a consequence, these allergens, respiratory problems or sensitization have been observed in this group $(16,17)$. Specifically, 
Swedish bakers, and chiefly those who worked in this profession in the 1970s and 1980s, have been reported as having an elevated risk of some immunological responses $(18,19)$.

Yet the relationship between allergic conditions and MM is not well understood. The hypothesis that chronic immune stimulation might cause myeloma was based on the assumption that antigenic stimulation could increase the likelihood of a malignant transformation in mature B cells. More recent research has shown that malignant transformation in myeloma occurs at the level of the pre-B or stem cell, which is not stimulated by antigen. Nonetheless, chronic immune stimulation could have a promotional effect on myeloma, though there is no experimental evidence to support such an hypothesis (2). Due to the discrepancy in the results obtained in the various epidemiologic studies, it is reasonable to surmise that, if an association were to exist between chronic exposure to sensitizing agents and risk of myeloma, its biological mechanism would be complex and might be influenced by the type of allergen, individual susceptibility, simultaneous exposure to different agents, or to other, as yet unknown factors.

This study indicates an elevated incidence of $\mathrm{MM}$ in the agriculture/forestry/fishing sector, and in bakers and pastry cooks. Workers exposed to HMW sensitizing agents, particularly bakers and pastry cooks, also registered a high risk, as did those occupations with occasional, though intense, exposures to pesticides. Some of these results should provide stimulus for further studies, particularly in the bread-and pastry-making sector where no association with this tumor has previously been described.

\section{References}

1. Alexander DD, Mink PJ, Adami HO, et al. Multiple myeloma: a review of the epidemiologic literature. Int $\mathrm{J}$ Cancer 2007;120 Suppl 12:40-61

2. De Roos AJ, Baris D, Weiss NS, Herrinton LJ. Multiple myeloma. In: Schottenfeld D, Fraumeni Jr JF, editors. Cancer Epidemiology and Prevention. Third edition.New York: Oxford University Press; 2006. p. 919-45.

3. Baris D, Silverman DT, Brown LM, et al. Occupation, pesticide exposure and risk of multiple myeloma. Scand J Work Environ Health 2004;30:215-22.

4. Khuder SA, Mutgi AB. Meta-analyses of multiple myeloma and farming. Am J Ind Med 1997;32:510-6. 
5. Morgan GJ, Davies FE, Linet M. Myeloma aetiology and epidemiology. Biomed Pharmacother 2002;56:22334.

6. Lope V, Pollan M, Gustavsson P, et al. Occupation and thyroid cancer risk in Sweden. J Occup Environ Med 2005;47:948-57.

7. Perez-Gomez B, Pollan M, Gustavsson P, et al. Cutaneous melanoma: hints from occupational risks by anatomic site in Swedish men. Occup Environ Med 2004;61:117-26.

8. Barlow L, Eklund G. Opening of a new database for research scientists. (In Swedish). Lakartidningen 1995;92:1344-7.

9. Centre for epidemiology. Cancer -Miljöregistret 1960-70. Swedish National Board of Health and Welfare 1994

10. Swedish Standard Industrial Classification of all Economic Activities. Second edition of the 1969 standard, Statistiska Centralbyran, Meddelanden I samordningsfragor, 9.Stockholm: Statistiska Centralbyrån (National Central Bureau of Statistics); 1977.

11. Jarvholm B. Work life and health (in Swedish). Stockolm: National Board of Occupational Safety and Health; 1996.

12. Kennedy SM, Le Moual N, Choudat D, Kauffmann F. Development of an asthma specific job exposure matrix and its application in the epidemiological study of genetics and environment in asthma (EGEA). Occup Environ Med 2000;57:635-41.

13. Breslow NE, Day NE. Statistical methods in cancer research. Volume II - The design and analysis of cohort studies. IARC Sci Publ 1987;1-406.

14. Oyer P. Wage Structure and Labor Mobility in Sweden, 1970-1990. In: Lazear EP, Shaw KL, editors. Wage Structure, Raises and Mobility: International Comparisons of the Structure of Wages Within and Across Firms. National Bureau of Economic Research. In press; 2006.

15. Blair A, Sandler DP, Tarone R, et al. Mortality among participants in the agricultural health study. Ann Epidemiol 2005;15:279-85.

16. Houba R, Doekes G, Heederik D. Occupational respiratory allergy in bakery workers: a review of the literature. Am J Ind Med 1998;34:529-46.

17. Brisman J. Baker's asthma. Occup Environ Med 2002;59:498-502. 
18. Brisman J, Jarvholm B. Bakery work, atopy and the incidence of self-reported hay fever and rhinitis. Eur Respir J 1999;13:502-7.

19. Brisman SJ, Jarvholm BG. Occurrence of self-reported asthma among Swedish bakers. Scand J Work Environ Health 1995;21:487-93. 
Table 1: Multiple myeloma risk among men workers by sector and occupation, adjusted for age, period and geographical area.

Whole Cohort

Subcohort $1960=1970$

OCCUPATION

Cases SIR $^{\dagger} \quad \mathbf{R R}^{\ddagger} \quad$ 95\% $\mathrm{Cl}^{\S}$ Cases $\mathrm{SIR}^{\dagger} \quad \mathbf{R R}^{\ddagger} \quad$ 95\% $\mathrm{Cl}^{\S}$

SECTOR 0: Professional and technical work

004 Chemical engineers \& technicians

007 Surveyors, measurers, cartographers

011 Chemists

023 Agricultural horticultural researchers/advisors

052 Teachers in theoretical subjects

054 Teachers of music, arts or crafts

085 Journalists, editors

SECTOR 1: Administrative and managerial

SECTOR 2: Bookkeeping \& clerical work

296 Insurance raters, claims adjusters

SECTOR 3: Sales work

301 Working proprietors, wholesale trade

332 Shop managers

SECTOR 4: Agriculture, forestry and fishing

401 Working prop. agricult., horticult. \& forestry enterprisers

412 Horticultural workers

431 Fishermen

SECTOR 5: Mining and quarrying

SECTOR 6: Transport \& communications

644 Road traffic supervisors

SECTOR 7: Production I

735 Black smiths \& forgers

738 Other metal processing work

744 Dental technicians

774 Frame, circular sawyers \& planers

782 Industrial spray painters

SECTOR 8: Production II

822 Baker \& pastry cooks

852 Plastic products workers

856 Stone cutters \& carvers

872 Crane \& hoist operators

874 Construction machine operators

SECTOR 9: Services and military work

904 Prison \& reformatory officials

908 Other civilian protective service work

932 Cleaners

941 Hairdressers, beauticians

\begin{tabular}{|c|c|c|c|c|c|c|c|}
\hline 465 & 98 & 0.98 & $0.89-1.08$ & 230 & 98 & 0.98 & $0.86-1.12$ \\
\hline 19 & 97 & 0.96 & $0.61-1.51$ & 11 & 145 & 1.44 & $0.80-2.61$ \\
\hline 6 & 195 & 1.95 & $0.88-4.34$ & 5 & 245 & 2.46 & $1.02-5.91$ \\
\hline 7 & 189 & 1.90 & $0.91-4.00$ & 4 & 284 & 2.87 & $1.08-7.65$ \\
\hline 6 & 201 & 2.00 & $0.90-4.45$ & 2 & 125 & 1.26 & $0.31-5.04$ \\
\hline 26 & 142 & 1.42 & $0.97-2.09$ & 16 & 180 & 1.80 & $1.10-2.94$ \\
\hline 12 & 146 & 1.46 & $0.83-2.58$ & 9 & 179 & 1.79 & $0.93-3.44$ \\
\hline 13 & 158 & 1.57 & $0.91-2.71$ & 7 & 137 & 1.36 & $0.65-2.86$ \\
\hline 106 & 87 & 0.87 & $0.71-1.05$ & 36 & 76 & 0.75 & 0.54- 1.04 \\
\hline 134 & 99 & 0.99 & $0.84-1.18$ & 32 & 94 & 0.94 & $0.66-1.33$ \\
\hline 7 & 141 & 1.40 & $0.67-2.94$ & 5 & 295 & 2.91 & $1.21-6.99$ \\
\hline 215 & 99 & 0.98 & $0.86-1.13$ & 86 & 92 & 0.91 & $0.74-1.13$ \\
\hline 14 & 142 & 1.41 & $0.83-2.39$ & 4 & 110 & 1.09 & $0.41-2.92$ \\
\hline 29 & 118 & 1.18 & $0.82-1.71$ & 12 & 122 & 1.22 & $0.69-2.16$ \\
\hline 498 & 116 & 1.18 & $1.07-1.30$ & 359 & 113 & 1.15 & $1.03-1.28$ \\
\hline 317 & 121 & 1.22 & $1.09-1.37$ & 259 & 115 & 1.16 & $1.02-1.32$ \\
\hline 35 & 131 & 1.32 & $0.94-1.84$ & 13 & 140 & 1.41 & $0.82-2.43$ \\
\hline 14 & 151 & 1.50 & $0.89-2.54$ & 13 & 168 & 1.67 & $0.97-2.88$ \\
\hline 23 & 132 & 1.32 & $0.88-2.00$ & 9 & 131 & 1.31 & $0.68-2.52$ \\
\hline 230 & 96 & 0.96 & $0.84-1.09$ & 147 & 103 & 1.02 & $0.86-1.20$ \\
\hline 12 & 148 & 1.49 & $0.84-2.62$ & 3 & 149 & 1.49 & $0.48-4.61$ \\
\hline 861 & 95 & 0.94 & $0.87-1.02$ & 447 & 94 & 0.93 & $0.84-1.03$ \\
\hline 14 & 125 & 1.26 & $0.75-2.13$ & 11 & 159 & 1.61 & $0.89-2.90$ \\
\hline 7 & 129 & 1.39 & $0.66-2.91$ & 3 & 223 & 2.42 & $0.78-7.50$ \\
\hline 6 & 334 & 3.33 & $1.50-7.42$ & 6 & 370 & 3.70 & $1.66-8.24$ \\
\hline 19 & 131 & 1.31 & $0.83-2.05$ & 4 & 130 & 1.32 & $0.50-3.52$ \\
\hline 11 & 127 & 1.27 & $0.70-2.30$ & 3 & 76 & 0.76 & $0.24-2.35$ \\
\hline 418 & 99 & 0.99 & $0.89-1.10$ & 139 & 85 & 0.85 & $0.72-1.01$ \\
\hline 23 & 154 & 1.53 & $1.02-2.31$ & 16 & 125 & 1.25 & $0.76-2.04$ \\
\hline 11 & 124 & 1.21 & $0.67-2.19$ & 0 & 0 & - & - \\
\hline 10 & 219 & 2.19 & $1.18-4.08$ & 4 & 163 & 1.65 & $0.62-4.40$ \\
\hline 13 & 128 & 1.31 & $0.76-2.26$ & 4 & 95 & 0.98 & $0.37-2.61$ \\
\hline 24 & 129 & 1.29 & $0.86-1.93$ & 11 & 146 & 1.46 & $0.81-2.64$ \\
\hline 177 & 107 & 1.07 & $0.92-1.25$ & 86 & 108 & 1.08 & $0.87-1.33$ \\
\hline 7 & 215 & 2.16 & $1.03-4.53$ & 5 & 340 & 3.40 & $1.41-8.18$ \\
\hline 19 & 123 & 1.24 & $0.79-1.94$ & 3 & 96 & 0.97 & $0.31-3,00$ \\
\hline 14 & 122 & 1.22 & $0.72-2.07$ & 2 & 124 & 1.24 & $0.31-4.95$ \\
\hline 12 & 126 & 1.26 & $0.71-2.22$ & 11 & 121 & 1.21 & $0.67-2.19$ \\
\hline 22 & 123 & 1.20 & $0.79-1.82$ & 17 & 115 & 1.12 & $0.70-1.81$ \\
\hline
\end{tabular}

981 Member of the armed forces

Occupations with at least 5 observed cases and $R R \geq 2.00$ or at least 10 observed cases and RR $\geq 1.20$ in whole cohort or in Subcohort.

†SIR: age and period standardised incidence ratio using the whole cohort as reference.

${ }^{\ddagger} \mathrm{RR}$ : Age, period and geographical area relative risk for each occupation in comparison with all others.

$\S 95 \% \mathrm{Cl}$ : Confidence intervals for the RR. 
Table 2: Multiple myeloma risk among women workers by sector and occupation, adjusted for age, period and geographical area.

Whole Cohort

Subcohort $1960=1970$

OCCUPATION*

Cases SIR $^{\dagger} \quad \mathbf{R R}^{\ddagger} \quad \mathbf{9 5} \% \mathrm{Cl}^{\S}$ Cases $\mathbf{S I R}^{\dagger} \quad \mathbf{R R}^{\ddagger} \quad \mathbf{9 5} \% \mathrm{Cl}^{\S}$

SECTOR 0: Professional and technical work

\begin{tabular}{|c|c|c|c|c|c|c|c|}
\hline 216 & 100 & 0.99 & $0.86-1.15$ & 92 & 106 & 1.06 & $0.86-1.31$ \\
\hline 12 & 185 & 1.86 & $1.06-3.29$ & 3 & 101 & 1.01 & $0.33-3.15$ \\
\hline 20 & 100 & 1,00 & $0.64-1.55$ & 20 & 129 & 1.29 & $0.83-2.00$ \\
\hline 16 & 114 & 1.14 & $0.70-1.87$ & 3 & 140 & 1.39 & $0.45-4.31$ \\
\hline 188 & 97 & 0.96 & $0.82-1.12$ & 48 & 111 & 1.09 & $0.82-1.46$ \\
\hline 35 & 101 & 1.01 & $0.72-1.41$ & 18 & 153 & 1.51 & $0.95-2.41$ \\
\hline 167 & 96 & 0.94 & $0.80-1.11$ & 62 & 99 & 0.97 & $0.75-1.26$ \\
\hline 85 & 101 & 1.01 & $0.81-1.26$ & 10 & 99 & 0.98 & $0.53-1.83$ \\
\hline 13 & 166 & 1.70 & $0.98-2.93$ & 4 & 175 & 1.78 & $0.67-4.75$ \\
\hline 0 & 0 & 0.00 & $0.00-$ & 0 & 0 & 0.00 & $0.00-$ \\
\hline 38 & 97 & 0.96 & $0.69-1.32$ & 11 & 77 & 0.76 & $0.42-1.38$ \\
\hline 100 & 104 & 1.08 & $0.88-1.33$ & 30 & 85 & 0.89 & $0.62-1.28$ \\
\hline 12 & 176 & 1.79 & $1.01-3.15$ & 1 & 185 & 1.85 & $0.26-13.16$ \\
\hline 14 & 174 & 1.73 & $1.02-2.93$ & 2 & 116 & 1.13 & $0.28-4.52$ \\
\hline 96 & 133 & 1.35 & $1.10-1.66$ & 26 & 152 & 1.53 & $1.04-2.26$ \\
\hline 13 & 209 & 2.06 & $1.20-3.57$ & 5 & 207 & 2.06 & $0.86-4.96$ \\
\hline 6 & 254 & 2.58 & $1.16-5.76$ & 2 & 256 & 2.54 & $0.63-10.16$ \\
\hline 17 & 125 & 1.27 & $0.78-2.04$ & 3 & 123 & 1.26 & $0.40-3.90$ \\
\hline 14 & 129 & 1.29 & $0.76-2.18$ & 3 & 168 & 1.68 & $0.54-5.22$ \\
\hline 376 & 96 & 0.94 & $0.84-1.06$ & 86 & 95 & 0.93 & $0.75-1.16$ \\
\hline 22 & 131 & 1.31 & $0.86-1.99$ & 9 & 149 & 1.48 & $0.77-2.85$ \\
\hline
\end{tabular}

042 Attendants in psychiatric care

053 Class teachers

SECTOR 1: Administrative and managerial

SECTOR 2: Bookkeeping \& clerical work

201 Bookkeepers \& office cashiers

SECTOR 3: Sales work

SECTOR 4: Agriculture, forestry and fishing

401 Working prop, agricult, horticult, \& forestry enterprisers

SECTOR 5: Mining and quarrying

SECTOR 6: Transport \& communications

SECTOR 7: Production I

750 Toolmakers, machine-tool setters \& operators

758 Other engineering \& building metal work

SECTOR 8: Production II

822 Baker \& pastry cooks

857 Paper \& paperboard product worker

881 Packers

883 Store \& warehouse workers

SECTOR 9: Services and military work

911 Catering supervisors

$22 \quad 131 \quad 1.31 \quad 0.86-1.99$

$9 \quad 149 \quad 1.48 \quad 0.77-2.85$

"Occupations with at least 5 observed cases and $R R \geq 2.00$ or at least 10 observed cases and RR $\geq 1.20$ in whole cohort or in Subcohort.

†SIR: age and period standardised incidence ratio using the whole cohort as reference.

₹RR: Age, period and geographical area relative risk for each occupation in comparison with all others.

$\$ 95 \% \mathrm{Cl}$ : Confidence intervals for the RR. 
Table 3: Multiple myeloma risk associated with occupational exposure to chemicals and sensitizing agents among men and women workers, adjusted for age, period and geographic area.

\begin{tabular}{|c|c|c|c|c|c|c|}
\hline \multirow{2}{*}{$\begin{array}{l}\text { Occupational } \\
\text { exposure factors }\end{array}$} & \multicolumn{3}{|c|}{ MEN } & \multicolumn{3}{|c|}{ WOMEN } \\
\hline & Cases & $\mathbf{R R}^{\dagger}$ & $95 \% \mathrm{Cl}^{\ddagger}$ & Cases & $\mathbf{R R}^{\dagger}$ & $95 \% \mathrm{Cl}^{\ddagger}$ \\
\hline \multicolumn{7}{|l|}{ Chemicals* } \\
\hline \multicolumn{7}{|l|}{ Asbestos } \\
\hline No exposure & 2072 & 1.00 & & 961 & 1.00 & \\
\hline Possible & 218 & 1.00 & $0.87-1.15$ & 0 & 0.00 & $0.00-$. \\
\hline Probable & 38 & 0.96 & $0.69-1.32$ & 1 & 4.86 & $0.68-34.56$ \\
\hline \multicolumn{7}{|l|}{ Metal compounds } \\
\hline No exposure & 2250 & 1.00 & & 962 & 1.00 & \\
\hline Possible & 27 & 1.15 & $0.78-1.68$ & 0 & 0.00 & $0.00-$ \\
\hline Probable & 51 & 0.87 & $0.66-1.15$ & 0 & 0.00 & $0.00-$ \\
\hline \multicolumn{7}{|c|}{ PAHs (combustion products) } \\
\hline No exposure & 2053 & 1.00 & & 950 & 1.00 & \\
\hline Possible & 86 & 0.98 & $0.79-1.21$ & 12 & 1.11 & $0.63-1.95$ \\
\hline Probable & 189 & 1.07 & $0.92-1.25$ & 0 & 0.00 & $0.00-$ \\
\hline \multicolumn{7}{|c|}{ Pesticides/herbicides peak exposures } \\
\hline No exposure & 1978 & 1.00 & & 942 & 1.00 & \\
\hline Possible & 350 & 1.20 & $1.07-1.34$ & 20 & 1.29 & $0.83-2.00$ \\
\hline \multicolumn{7}{|l|}{ Solvents } \\
\hline No exposure & 1922 & 1.00 & & 931 & 1.00 & \\
\hline Possible & 293 & 0.97 & $0.85-1.09$ & 23 & 1.20 & $0.79-1.81$ \\
\hline Probable & 113 & 1.11 & $0.92-1.35$ & 8 & 1.60 & $0.80-3.20$ \\
\hline \multicolumn{7}{|l|}{ Textile dust } \\
\hline No exposure & 2294 & 1.00 & & 926 & 1.00 & \\
\hline Possible & 15 & 0.65 & $0.39-1.09$ & 21 & 0.60 & $0.39-0.92$ \\
\hline Probable & 19 & 1.13 & $0.72-1.78$ & 15 & 0.75 & $0.45-1.25$ \\
\hline \multicolumn{7}{|l|}{ Sensitizing agents } \\
\hline \multicolumn{7}{|l|}{ Low molecular weight } \\
\hline No exposure & 1209 & 1.00 & & 609 & 1.00 & \\
\hline Probable & 524 & 0.99 & $0.89-1.10$ & 46 & 0.98 & $0.72-1.34$ \\
\hline \multicolumn{7}{|l|}{ High molecular weight } \\
\hline No exposure & 1693 & 1.00 & & 634 & 1.00 & \\
\hline Probable & 40 & 1.45 & $1.06-1.98$ & 21 & 1.59 & $1.02-2.49$ \\
\hline
\end{tabular}

${ }^{*}$ Occupational exposure factors with at least 10 probable exposed cases among men or women workers.

${ }^{\dagger}$ RR: age, period and geographical area relative risk for each chemical factor compared to no exposure, and relative risk for low molecular weight exposure adjusted for simultaneous exposure to high molecular weight exposure and vice versa.

$\neq 95 \% \mathrm{Cl}$ : confidence intervals for the RR. 